\title{
Bidding strategy for an energy storage facility
}

Nasrolahpour, Ehsan; Zareipour, Hamidreza; Rosehart, William D.; Kazempour, Jalal

Published in:

Proceedings of the 19th Power Systems Computation Conference

Publication date:

2016

Document Version

Peer reviewed version

Link back to DTU Orbit

Citation (APA):

Nasrolahpour, E., Zareipour, H., Rosehart, W. D., \& Kazempour, J. (2016). Bidding strategy for an energy storage facility. In Proceedings of the 19th Power Systems Computation Conference IEEE.

\section{General rights}

Copyright and moral rights for the publications made accessible in the public portal are retained by the authors and/or other copyright owners and it is a condition of accessing publications that users recognise and abide by the legal requirements associated with these rights.

- Users may download and print one copy of any publication from the public portal for the purpose of private study or research.

- You may not further distribute the material or use it for any profit-making activity or commercial gain

- You may freely distribute the URL identifying the publication in the public portal

If you believe that this document breaches copyright please contact us providing details, and we will remove access to the work immediately and investigate your claim. 


\title{
Bidding Strategy for an Energy Storage Facility
}

\author{
Ehsan Nasrolahpour*, Hamidreza Zareipour*, William D. Rosehart*, and S. Jalal Kazempour ${ }^{\dagger}$ \\ * Department of Electrical and Computer Engineering \\ University of Calgary \\ $\dagger$ Department of Electrical Engineering \\ Technical University of Denmark
}

\begin{abstract}
This paper studies operation decisions of energy storage facilities in perfectly and imperfectly competitive markets. In a perfectly competitive market, the storage facility is operated to maximize the social welfare. However, in a imperfectly competitive market, the storage facility operates to maximize its profit, while the market operator aims at maximizing the social welfare. In this case, the storage facility adapts its strategic behavior to take advantage of market conditions. To model the imperfectly competitive market, a bi-level optimization model is implemented to present the interactions between the storage facility and the market operator. In an illustrative test system, operation of the storage facility in these two market structures is compared and discussed.
\end{abstract}

Index Terms-Bidding strategy, Energy storage, Market operator, Mathematical Program with Equilibrium Constraints (MPEC)

A. Indices and Sets

$t \quad$ Index of time periods running from 1 to $N_{t}$.

$g \quad$ Index of generation units running from 1 to $N_{g}$.

$s \quad$ Index of energy storage systems running from 1 to $N_{s}$.

$d \quad$ Index of load demands running from 1 to $N_{d}$.

B. Parameters

$M C_{s}^{\text {dis }} \quad$ Marginal cost of energy storage system $s$ in the discharging mode, (\$/MWh).

$M C_{s}^{c h} \quad$ Marginal cost of energy storage system $s$ in the charging mode, (\$/MWh).

$M C_{g} \quad$ Marginal cost of generation unit $g,(\$ / \mathrm{MWh})$.

$P_{s}^{d i s, \max }$ Maximum limit on generated power of energy storage system $s$ in the discharging mode, (MW).

$P_{s}^{c h, \max }$ Maximum limit on stored power of energy storage system $s$ in the charging mode, (MW).

$E_{s}^{\max }$ Maximum limit on stored energy of energy storage system $s$, (MWh).

$E_{s}^{i n i} \quad$ Initial value of stored energy of energy storage system $s$, (MWh).

$\alpha_{s} \quad$ A non-negative factor to control stored energy of energy storage system $s$ for the the next time horizon.

$\eta_{s} \quad$ Efficiency of energy storage system $s$.

$P_{g}^{\max } \quad$ Capacity of generation unit $g$, (MW).

$P_{g}^{i n i} \quad$ Initial value of generated power of generation unit $g$, (MW).

$P_{d, t}^{\max } \quad$ Maximum load demand of consumer $d$ at time $t$, (MW).
$U_{d, t} \quad$ Bid price of load demand $d$ at time $t,(\$ / M W h)$.

C. Variables

$u_{s, t}^{\text {dis }} \quad$ Binary decision variable to indicate if energy storage system $s$ is in the discharging mode at time $t$.

$u_{s, t}^{c h} \quad$ Binary decision variable to indicate if energy storage system $s$ is in the charging mode at time $t$.

$u_{s, t}^{i d l} \quad$ Binary decision variable to indicate if energy storage system $s$ is in the idle mode at time $t$.

$\bar{P}_{s, t}^{\text {dis }} \quad$ Quantity offer by energy storage system $s$ in the discharging mode at time $t,(\mathrm{MW})$.

$\bar{P}_{s, t}^{c h} \quad$ Quantity bid by energy storage system $s$ in the charging mode at time $t$, (MW).

$p_{g, t} \quad$ Power generated by generation unit $g$ at time $t$, (MW).

$p_{s, t}^{d i s} \quad$ Power generated by energy storage system $s$ in the discharging mode at time $t,(\mathrm{MW})$.

$p_{s, t}^{c h} \quad$ Power stored by energy storage system $s$ in the charging mode at time $t,(\mathrm{MW})$.

$o_{s, t}^{d i s} \quad$ Price offer by energy storage system $s$ in the discharging mode at time $t,(\$ / \mathrm{MWh})$.

$o_{s, t}^{c h} \quad$ Price bid by energy storage system $s$ in the charging mode at time $t,(\$ / \mathrm{MWh})$.

$e_{s, t} \quad$ Energy stored in energy storage system $s$ at time $t$, (MWh).

$p_{d, t} \quad$ Power consumed by load demand $d$ at time $t$, (MW).

$\mu, \lambda \quad$ Dual variables corresponding to the lower level constraints.

\section{INTRODUCTION}

Large-scale electric energy storage is being considered as one of the potential enablers for a more flexible grid, and thus is expected to grow significantly over the coming years [1]. As an example, California has set a goal of feeding $33 \%$ of its energy through renewable resources [2], 80\% of which to be coming from wind and solar generation [3]. To accommodate this much intermittent energy, the California Public Utilities Commission has mandated the three big utilities to have 1325 MW of energy storage in operation by 2024 [4]. Besides, the Federal Energy Regulatory Commission (FERC) allows energy storage, as one of so-called "non-generation" resources, to participate in electricity markets [5]. Therefore, exploring 
optimal operational strategies for large-scale energy storage resources is of particular interest.

Over the past few years, a number of works have been reported which are focused on operation of energy storage. In particular, the existing literature on the optimal operation of energy storage systems can be divided into two broad categories depending on who operates the facility. In the first category, energy storage facilities are operated in a centrally controlled market. In such context, energy storage may serve a number of purposes, such as, improving system reliability or facilitating high renewable energy penetration. In [6] and [7], a compressed air energy storage and a pumped-storage hydro, as the two largest worldwide installed storage facility technologies, are employed to reduce the total generation cost for a system with high wind penetration. In [8], impacts of energy storage in terms of power system reliability on a system with integrated renewable energy resources are discussed. In [9], plug-in vehicles as mobile storage devices are used to maximize the utilization of renewable energy resources in terms of cost and emission. In [10], the optimal capacity and operation for a storage facility is optimized to minimize the total system operation cost and also its impact on price is explored. In this category of studies, energy storage is not considered as an independent for-profit entity, and thus, its profitability is not addressed.

In the second category, energy storage is operated as a merchant and for-profit entity. These studies can further be divided into two groups depending on how the storage facility would impact market prices. In the first group, the storage facilities are treated as price-takers, i.e., they are assumed to be small enough such that their actions do not affect market prices. In such context, operation of the storage facilities is optimized under the assumption that the future market prices are known in advance. Hence, the storage operator would use historical price data, and optimizes its operation decisions accordingly. In [11], an energy storage facility is owned by a wind farm and its operation decisions are made according to the wind farm's power production estimates in order to maximize the owner's profit. In [12], a few distributed storage systems are operated by an aggregator to meet the local load demand at the minimum cost. In [13], a storage facility is operated by an independent utility to maximize its profit in both energy and reserve markets. In the second group, the energy storage facilities are considered as price-makers [14], i.e., they are large and their actions actually impact market prices. In this group of studies, the facilities, which have the price-maker capability and their objective is to maximize their profit, can bid not necessary at their marginal cost. This may lead to an imperfectly competitive market environment.

To investigate the optimal bidding strategies of market players in an imperfect competitive market environment, several studies have reported the application of Mathematical Program with Equilibrium Constraints (MPEC) models [14], [15], [16], [17], [18], [19]. The MPEC approach for electricity market modeling was initially used in the pioneering work [15]. Other studies followed by using the MPEC approach in other electricity market studies, such as, on strategic behavior of a producer in [16], the optimal investment of a strategic producer in [17], the strategic offering of a wind power producer in [18], the strategic bidding of a large consumer in [19], and the strategic bidding of a storage facility [14].

In addition, several relevant papers exist in the technical literature addressing the perfect and imperfect competitions in power systems, e.g., [20] referring to the offering strategy of producers, and [21] referring to the transmission expansion planning. In these two papers, a Cournot model is used to model the imperfect competition. Their findings show that each market player with market power capability can potentially adapt its strategy considering the market conditions to alter the market-clearing outcomes to its own benefit. In this paper, we compare the storage facility's operation in perfectly and imperfectly competitive markets. The operation of storage facility for each hour in both cases is discussed with details.

The main contribution of this paper is to compare the storage facility's operation in two market circumstances. This study provides a good understanding of market structures' impacts on storage facilities' operation decisions.

The rest of the paper is organized as follows. The methodology and formulation are provided in Section II. The results are presented and discussed in Section III. The paper is concluded in Section IV.

\section{Methodology And Formulation}

In this section, the proposed method for determining the optimal bidding strategy of a storage facility in perfectly and imperfectly competitive market structures are presented.

\section{A. Storage Facilities' Operation in a Perfectly Competitive Market}

In a perfectly competitive market, all market players offer at their marginal costs. The market operator accepts the bids and offers to maximize the social welfare and satisfy the physical market constraints. This problem is formulated in (a.1)-(a.6) as given below:

Min. $\begin{aligned} \sum_{t=1}^{N_{t}} & {\left[\sum_{g=1}^{N_{g}} M C_{g} \cdot p_{g, t}+\sum_{s=1}^{N_{s}} M C_{s, t}^{d i s} \cdot p_{s, t}^{d i s}\right.} \\ & \left.-\sum_{s=1}^{N_{s}} M C_{s, t}^{c h} \cdot p_{s, t}^{c h}-\sum_{d=1}^{N_{d}} U_{d, t} \cdot p_{d, t}\right]\end{aligned}$

S.t.

$\sum_{d=1}^{N_{d}} p_{d, t}-\sum_{s=1}^{N_{s}}\left[p_{s, t}^{d i s}-p_{s, t}^{c h}\right]-\sum_{g=1}^{N_{g}} p_{g, t}=0 \quad: \lambda_{t} ; \quad \forall t$

$0 \leq p_{g, t} \leq P_{g}^{\max } \forall g, \forall t$

$0 \leq p_{d, t} \leq P_{d, t}^{\max } \quad \forall d, \forall t$

$0 \leq p_{s, t}^{\text {dis }} \leq P_{s}^{\text {dis,max }} \forall s, \forall t$

$0 \leq p_{s, t}^{c h} \leq P_{s}^{c h, \max } \forall s, \forall t$ 
The objective function of this problem seeks to minimize the negative of social welfare, which is the difference between generation cost and demand utility, as presented in (a.1). (a.2) enforces the energy balance, whose dual variable provides the system marginal cost (SMC). (a.3) binds generators' production levels. (a.4) binds the consumption level of load demands. (a.5) and (a.6) enforce the energy storage facilities to discharge/charge between zero and their maximum capacities, respectively.

\section{B. Storage Facilities' Operation in an Imperfectly Competitive Market Environment}

In this section, the storage facility's operation in an imperfectly competitive market environment is formulated using a bi-level model. This model has two components, i.e., an upper level problem modeling the operation of the storage facility and the lower problem, i.e., modeling the marketclearing process. The upper and lower level problems are first discussed, and then, the bi-level model is transformed into a single-level MPEC and solved accordingly.

The upper level problem seeks to maximize the storage facility's profit, as formulated in (b.1)-(b.10):

$$
\begin{aligned}
& \text { Min. } \sum_{t=1}^{N_{t}} \sum_{s=1}^{N_{s}}\left[\left(\lambda_{t}+M C_{s}^{c h}\right) \cdot p_{s, t}^{c h}\right. \\
& \left.-\left(\lambda_{t}-M C_{s}^{d i s}\right) \cdot p_{s, t}^{d i s}\right]
\end{aligned}
$$

S.t.

$$
\begin{aligned}
& u_{s, t}^{d i s}+u_{s, t}^{c h}+u_{s, t}^{i d l}=1 \quad \forall s, \forall t \\
& 0 \leq \bar{p}_{s, t}^{d i s} \leq u_{s, t}^{d i s} \cdot P_{s}^{d i s, \max } \forall s, \forall t \\
& 0 \leq \bar{p}_{s, t}^{c h} \leq u_{s, t}^{c h} \cdot P_{s}^{c h, \max } \forall s, \forall t \\
& o_{s, t}^{d i s} \geq 0 \quad \forall s, \forall t \\
& o_{s, t}^{c h} \geq 0 \quad \forall s, \forall t \\
& 0 \leq e_{s, t} \leq E_{s}^{\text {max }} \forall s, \forall t \\
& e_{s, t}=E_{s}^{\text {ini }}-p_{s, t}^{d i s}+\eta_{s} \cdot p_{s, t}^{c h} \quad \forall s, t=1 \\
& e_{s, t}=e_{s,(t-1)}-p_{s, t}^{d i s}+\eta_{s} \cdot p_{s, t}^{c h} \forall s, \forall t>1 \\
& e_{s, t}=\alpha_{s} \cdot E_{s}^{i n i} \forall s, t=N_{t}
\end{aligned}
$$

The objective function (b.1) is composed of two terms. The first term is associated with the cost incurred for purchasing and storing energy in the charging mode. It is composed of the cost of buying energy from market and the costs of that might be associated to storing this energy by the energy storage charging device (e.g., the costs of compression in the case of compressed air energy storage). The second term is associated with the energy storage profit in discharging mode, which is calculated through the revenue achieved by selling energy to the market minus the costs that might be associated with releasing the stored energy (e.g., the expanding costs in the case of compressed air energy storage). Note that $\operatorname{SMC}\left(\lambda_{i}\right)$ is endogenously obtained from the lower level problem.
Three operation modes for the energy storage facility are considered in (b.2), which are discharging, charging, and idling, i.e., when the facility is operating in neither discharging nor charging modes. (b.3) and (b.4) bind the energy storage quantity offers and bids, respectively. (b.5) and (b.6) enforce the non-negativity of the energy storage offer and bid prices, respectively. (b.7) refers to upper and lower bounds for the storage facility energy reservoir. (b.8) and (b.9) represent the energy storage state of charge for the first and rest of hours, respectively. (b.10) is designed to specify the state of charge at the end of planning horizon. For sake of simplicity, transmission system constraints are not modeled.

In the lower level problem, the market operator clears the market based on submitted bids and offers. The storage facility strategically offers/bids in both quantity and price. We assume that other market participants submit their offer and bid prices based on their marginal cost/utility. This assumption enables us to model the problem of this paper as an MPEC problem, in line with [15]. The lower level problem is formulated in by (c.1)-(c.6), which are similar to (a.1)-(a.6). However, (a.5) and (a.6) are substituted by (c.5) and (c.6) which restrict the discharging and charging power of energy storage facilities by their submitted quantity offers and bids.

$$
\begin{aligned}
& \text { Min. } \sum_{t=1}^{N_{t}}\left[\sum_{g=1}^{N_{g}} M C_{g} \cdot p_{g, t}+\sum_{s=1}^{N_{s}} o_{s, t}^{d i s} \cdot p_{s, t}^{d i s}\right. \\
& \left.-\sum_{s=1}^{N_{s}} o_{s, t}^{c h} \cdot p_{s, t}^{c h}-\sum_{d=1}^{N_{d}} U_{d, t} \cdot p_{d, t}\right]
\end{aligned}
$$

S.t.

$\sum_{d=1}^{N_{d}} p_{d, t}-\sum_{s=1}^{N_{s}}\left[p_{s, t}^{d i s}-p_{s, t}^{c h}\right]-\sum_{g=1}^{N_{g}} p_{g, t}=0 \quad: \lambda_{t} ; \quad \forall t$

$0 \leq p_{g, t} \leq P_{g}^{\max }: \mu_{g, t}^{\min }, \mu_{g, t}^{\max } ; \forall g, \forall t$

$0 \leq p_{d, t} \leq P_{d, t}^{\max }: \mu_{d, t}^{\min }, \mu_{d, t}^{\max } ; \quad \forall d, \forall t$

$0 \leq p_{s, t}^{\text {dis }} \leq \bar{p}_{s, t}^{\text {dis }}: \mu_{s, t}^{\text {dis,min }}, \mu_{s, t}^{\text {dis, } \max } ; \quad \forall s, \forall t$

$0 \leq p_{s, t}^{c h} \leq \bar{p}_{s, t}^{c h}: \mu_{s, t}^{c h, \min }, \mu_{s, t}^{c h, \max } ; \forall s, \forall t$

The dual variables pertaining to constraints above are specified at each equation. Note that the binary decisions, as well as the offering and bidding decisions of the energy storage (price and quantity) are upper level variables. However, they are fixed values within the lower level problem. Therefore, the lower level problem is continuous, linear, and thus convex [19].

In order to transfer the bi-level model into a single-level MPEC, the primal-dual transformation is applied [22]. (d.1)(d.7) provided in the Appendix give the dual constraints of the lower level problem. Equation (d.8) refers to the strong duality condition corresponding to the lower level problem, which enforces the equality of its primal and dual objective function values at the optimal solution. 
TABLE I

GENERATION UNITS CHARACTERISTICS

\begin{tabular}{ccccccc}
\hline Unit No. & Bus No. & $\begin{array}{c}P_{g}^{\max } \\
(\mathrm{MW})\end{array}$ & $\begin{array}{c}M C_{g} \\
(\$ / \mathrm{MWh})\end{array}$ & $\begin{array}{c}R U_{g}^{\max } \\
(\mathrm{MW} / \mathrm{h})\end{array}$ & $\begin{array}{c}R D_{g}^{\max } \\
(\mathrm{MW} / \mathrm{h})\end{array}$ & $\begin{array}{c}P_{g}^{\text {ini }} \\
(\mathrm{MW})\end{array}$ \\
\hline G1 & 1 & 100 & 12 & 20 & 20 & 100 \\
G2 & 2 & 75 & 20 & 12 & 12 & 75 \\
G3 & 6 & 50 & 50 & 10 & 10 & 0 \\
G4 & 6 & 50 & 300 & 10 & 10 & 0 \\
\hline
\end{tabular}

TABLE II

STORAGE FACILITY CHARACTERISTICS

\begin{tabular}{cccccc}
\hline $\begin{array}{l}\text { Storage } \\
\text { facility }\end{array}$ & Bus No. & $\begin{array}{c}P_{s}^{\text {dis, } \max } \\
(\mathrm{MW})\end{array}$ & $\begin{array}{c}P_{s}^{\text {ch,max }} \\
(\mathrm{MW})\end{array}$ & $\begin{array}{c}M C_{s}^{\text {dis }} \\
(\$ / \mathrm{MWh})\end{array}$ & $\begin{array}{c}M C_{s}^{c h} \\
(\$ / \mathrm{MWh})\end{array}$ \\
\hline 1 & 5 & 20 & 15 & 18 & 1 \\
\hline
\end{tabular}

The single-level MPEC problem includes upper level problem (b.1)-(b.10), primal constraints (c.2)-(c.6), dual constraints (d.1)-(d.7) and strong duality condition (d.8). There are some non-linear terms in the MPEC formulation due to the product of prices and quantities in (d.8) and (b.1). Note that since there are also binary variables within MPEC, it is in fact a mixedinteger non-linear programming problem, while there is no off-the-shelf solver available to solve this kind of problems. Thus, pursuing linearity, the strong duality condition as well as the primal inequality constraints and the non-negativity conditions can be replaced by the set of complementary conditions obtained by Karush-Kuhn-Tucker (KKT) conditions of the lower level problem (e.1)-(e.8) [22], [23].

Each of complementarity conditions can be linearized by its mixed-integer linear equivalent as explained in [24]. Also, the linear equivalent of objective function (b.1) can be driven from dual conditions, the strong duality condition, and the complementarity conditions [16]. The linear objective function is stated in Appendix as (f.1).

\section{NumericAl RESUlts}

In this section, a six-bus system [25] is studied to demonstrate the storage operation in two market structures.

Technical characteristics of the generation units are given in Tables I. The storage facility technical characteristics are provided in Table II. The energy storage's charging and discharging components are modeled separately. This is mainly inspired by the operation of a compressed air energy storage facility [26]. This separation provides further flexibility in modeling and analysis of different storage technologies. The capacity of storage facility's energy reservoir is assumed to be $100 \mathrm{MWh}$. In this test system, a period of 24 hours is considered as the planning horizon. The planning horizon for the bidding strategy of energy storage is selected to reasonably match the storage reservoir size [27], larger reservoirs may require a longer planning period. It is assumed that the facility starts empty and comes back to the same state at the end of the planning horizon. Also, without losing generality, the efficiency of both charge and discharge devices are supposed to be $100 \%$. The hourly load distribution over the 24 hours horizon is shown in Fig. 1. The load is distributed equally

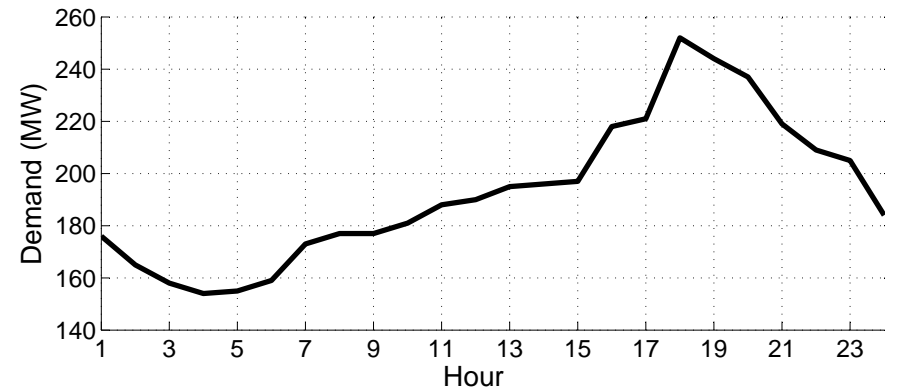

Figure 1. Demand over 24 hours, $\left(\sum_{d} P_{d, t}^{\max }, \forall t\right)$

among buses 3 and 4 . All loads bid at \$450/MWh for all hours.

The following test cases are studied:

- Case 1: The energy storage, which is operated by the market operator, participates in the perfectly competitive market.

- Case 2: The energy storage, which is controlled by an independent operator, bids and offers strategically to maximize its profit in the imperfectly competitive market.

Case 1: In this case, we assume the storage facility participates in the market as a non-strategic player, and thus, the market is perfectly competitive. The detailed numerical results for this case are presented in Table III. We have also presented the consumption values at each hour in this table. The purpose of this case is to demonstrate a simple case where the numerical results could be tracked. Also, we will compare the results of other cases to this base case.

In the first hour, the load is $176 \mathrm{MW}$ and is supplied by generation units G1, G2, and G3. Since generation units G1 and G2 are dispatched at their full capacity in this hour, the marginal cost of generation unit G3 sets the SMC, which is $\$ 50 / \mathrm{MWh}$. In the second hour, the load is $165 \mathrm{MW}$ and the storage facility is charged at a $10 \mathrm{MW}$ rate. The SMC is cleared at $\$ 31 / \mathrm{MWh}$, which is less than the marginal cost of the generation unit who can supply the next MW demand, i.e., unit G3. To justify this value, observe that in this hour, the next MW could be supplied by unit G2 if the storage facility was being charged one less MW. The value of this MW is equal to the would be selling price when discharging, i.e., $\$ 50 / \mathrm{MWh}$ at either of hours except for hours that the storage is fully dispatched (e.g., hour 18), minus the storage facility's operation costs in charging and discharging modes, i.e., $18+1=19 \$ / M W h$. Thus, the SMC of the second hour is calculated $50-19=31 \$ / M W h$. Hours 3-6 are considered as low demand periods and thus, the storage facility is charged at the maximum rate, i.e., $15 \mathrm{MW}$. In these hours, the SMC is determined by the marginal cost of generation unit G2, i.e., $\$ 20 / M W h$. Similar to hour 2 , the SMC at hour 7 is $\$ 31 / \mathrm{MWh}$. For hours $8-17$, the SMC is $\$ 50 / \mathrm{MWh}$, which is equal to the marginal cost of generation unit G3. At hour 18, the load demand is $246 \mathrm{MW}$ and the SMC is determined by the marginal cost of the most expensive unit, i.e., G4. Note 
TABLE III

SCHEDUle RESUlTS IN CASE 1: THE ENERGY STORAGE IS A NON-STRATEGIC PLAYER

\begin{tabular}{|c|c|c|c|c|c|c|c|}
\hline \multirow[b]{2}{*}{ Hour } & \multirow[b]{2}{*}{$\begin{array}{c}p_{d, t} \\
(\mathrm{MW})\end{array}$} & \multirow{2}{*}{$\begin{array}{c}p_{s, t}^{d i s} / p_{s, t}^{c h} \\
(\mathrm{MW})^{*}\end{array}$} & \multicolumn{4}{|c|}{$p_{g, t}$} & \multirow{2}{*}{$\begin{array}{c}\lambda_{i, t} \\
(\$ / \mathrm{MWh})\end{array}$} \\
\hline & & & $G_{1}$ & $G_{2}$ & $\begin{array}{l}G_{3} \\
V)\end{array}$ & $G_{4}$ & \\
\hline 1 & 176 & & 100 & 75 & 1 & 0 & 50 \\
\hline 2 & 165 & -10 & 100 & 75 & 0 & 0 & 31 \\
\hline 3 & 158 & -15 & 100 & 73 & 0 & 0 & 20 \\
\hline 4 & 154 & -15 & 100 & 69 & 0 & 0 & 20 \\
\hline 5 & 155 & -15 & 100 & 70 & 0 & 0 & 20 \\
\hline 6 & 159 & -15 & 100 & 74 & 0 & 0 & 20 \\
\hline 7 & 173 & -2 & 100 & 75 & 0 & 0 & 31 \\
\hline 8 & 177 & & 100 & 75 & 2 & 0 & 50 \\
\hline 9 & 177 & & 100 & 75 & 2 & 0 & 50 \\
\hline 10 & 181 & & 100 & 75 & 6 & 0 & 50 \\
\hline 11 & 188 & & 100 & 75 & 13 & 0 & 50 \\
\hline 12 & 190 & & 100 & 75 & 15 & 0 & 50 \\
\hline 13 & 195 & & 100 & 75 & 20 & 0 & 50 \\
\hline 14 & 196 & & 100 & 75 & 21 & 0 & 50 \\
\hline 15 & 197 & & 100 & 75 & 22 & 0 & 50 \\
\hline 16 & 218 & & 100 & 75 & 43 & 0 & 50 \\
\hline 17 & 221 & 12 & 100 & 75 & 34 & 0 & 50 \\
\hline 18 & 252 & 20 & 100 & 75 & 50 & 7 & 300 \\
\hline 19 & 244 & 20 & 100 & 75 & 49 & 0 & 50 \\
\hline 20 & 237 & 20 & 100 & 75 & 42 & 0 & 50 \\
\hline 21 & 219 & & 100 & 75 & 44 & 0 & 50 \\
\hline 22 & 209 & & 100 & 75 & 34 & 0 & 50 \\
\hline 23 & 205 & & 100 & 75 & 30 & 0 & 50 \\
\hline 24 & 184 & & 100 & 75 & 9 & 0 & 50 \\
\hline
\end{tabular}

TABLE IV

STORAGE FACILITY AND GENERATION UNITS PROFIT (\$1000)

\begin{tabular}{ccccccc}
\hline Case No. & Storage & G1 & G2 & G3 & G4 & $\begin{array}{c}\text { All Gen. } \\
\text { units }\end{array}$ \\
\hline Case 1 & 5.660 & 100.4 & 60.9 & 12.5 & 0 & 173.8 \\
Case 2 & 13.542 & 148.2 & 96.75 & 37.5 & 0 & 282.45 \\
\hline
\end{tabular}

that for hours 19 and 20, operation of the storage facility has led to a lower SMC of $\$ 50 / \mathrm{MWh}$. This is because if the storage facility were not operating, the demand would have been met by generation unit G4, and the SMC would have been $\$ 300 / \mathrm{MWh}$ at these two hours. However, since the storage facility discharges energy back to the system during these hours, the SMC remains at the marginal cost of unit G3, i.e., $\$ 50 / \mathrm{MWh}$. Thus, operation of the storage has reduced the market price for theses hours. For the remaining hours, i.e., $21-24$, unit G3 sets the price at $\$ 50 / \mathrm{MWh}$. The total profit in this case is $\$ 5660$ for the storage facility, and $\$ 173800$ for the rest of the fleet. The profits of the storage facility and other generation units for this case, and all other cases, are summarized in Table IV.

Case 2: The market outcomes for this case are presented in Table V. The results obtained for hour 1 are identical to those of Base Case. For hour 2, the storage facility strategically bids to buy $10 \mathrm{MW}$ at $\$ 20 / \mathrm{MWh}$, which is identical to the marginal cost of generation unit G2. The storage facility bids such that there is no need to dispatch generation unit G3. Thus, the demand is supplied by generation units G1 and G2. The SMC for this hour is identical to the marginal cost of the last generation unit dispatched and the bid price of the last demand supplied (i.e., storage), that is $\$ 20 / \mathrm{MWh}$. For hours 3-7, the storage facility price bid is the same as hour 2 . The storage
TABLE $\mathrm{V}$

SCHEDULE RESUlTS IN CASE 2: THE STORAGE FACILITY PLAYS STRATEGICALLY

\begin{tabular}{|c|c|c|c|c|c|c|c|c|}
\hline \multirow[b]{2}{*}{ Hour } & \multirow[b]{2}{*}{$\begin{array}{c}p_{d, t} \\
(\mathrm{MW})\end{array}$} & \multicolumn{2}{|c|}{ Storage facility } & \multicolumn{4}{|c|}{$p_{g, t}$} & \multirow[b]{2}{*}{$\begin{array}{c}\lambda_{i, t} \\
(\$ / \mathrm{MWh})\end{array}$} \\
\hline & & $\begin{array}{l}p_{s, t}^{\text {dis }} / p_{s, t}^{c h} \\
\text { (MW) }\end{array}$ & $\begin{array}{l}o_{s, t}^{d i s} / o_{s, t}^{c h} \\
\text { (\$/MWh) }\end{array}$ & $G_{1}$ & \multicolumn{3}{|c|}{ (MW) } & \\
\hline 1 & 176 & & & 100 & 75 & 1 & 0 & 50 \\
\hline 2 & 165 & -10 & 20 & 100 & 75 & 0 & 0 & 20 \\
\hline 3 & 158 & -15 & 20 & 100 & 73 & 0 & 0 & 20 \\
\hline 4 & 154 & -15 & 20 & 100 & 69 & 0 & 0 & 20 \\
\hline 5 & 155 & -15 & 20 & 100 & 70 & 0 & 0 & 20 \\
\hline 6 & 159 & -15 & 20 & 100 & 74 & 0 & 0 & 20 \\
\hline 7 & 173 & -2 & 20 & 100 & 75 & 0 & 0 & 20 \\
\hline 8 & 177 & & & 100 & 75 & 2 & 0 & 50 \\
\hline 9 & 177 & & & 100 & 75 & 2 & 0 & 50 \\
\hline 10 & 181 & & & 100 & 75 & 6 & 0 & 50 \\
\hline 11 & 188 & & & 100 & 75 & 13 & 0 & 50 \\
\hline 12 & 190 & & & 100 & 75 & 15 & 0 & 50 \\
\hline 13 & 195 & & & 100 & 75 & 20 & 0 & 50 \\
\hline 14 & 196 & & & 100 & 75 & 21 & 0 & 50 \\
\hline 15 & 197 & 20 & 50 & 100 & 75 & 2 & 0 & 50 \\
\hline 16 & 218 & & & 100 & 75 & 43 & 0 & 50 \\
\hline 17 & 221 & & & 100 & 75 & 46 & 0 & 50 \\
\hline 18 & 252 & 20 & 300 & 100 & 75 & 50 & 7 & 300 \\
\hline 19 & 244 & 19 & 300 & 100 & 75 & 50 & 0 & 300 \\
\hline 20 & 237 & 12 & 300 & 100 & 75 & 50 & 0 & 300 \\
\hline 21 & 219 & & & 100 & 75 & 44 & 0 & 50 \\
\hline 22 & 209 & & & 100 & 75 & 34 & 0 & 50 \\
\hline 23 & 205 & 1 & 50 & 100 & 75 & 29 & 0 & 50 \\
\hline 24 & 184 & & & 100 & 75 & 9 & 0 & 50 \\
\hline
\end{tabular}

facility stays in the idle mode during hours 8-14 and 16-17, and discharges at its maximum level at hour 15. For hour 18, it strategically offers its maximum discharge level at a price identical to the marginal cost of unit G4. This way, the SMC is determined by the marginal cost of unit G4, $\$ 300 / \mathrm{MWh}$. For hour 19, the storage facility offers strategically 19 MW at $\$ 300 / \mathrm{MWh}$. Through this strategy, generation unit G3 is dispatched to its maximum level and the next MW should be supplied by unit G4. Therefore, the SMC stays at $\$ 300 / \mathrm{MWh}$. Similarly, for hour 20 , the storage facility offers $12 \mathrm{MW}$ at $\$ 300 / \mathrm{MWh}$. The storage facility offers its remaining one MWh during hour 23 at price of $\$ 50 / \mathrm{MWh}$ to meet the initial charging condition for next day.

The hourly SMCs for Cases 1 and 2 are illustrated in Fig. 2. The figure shows how the strategic behavior of the storage facility impacts the hourly SMCs, i.e., lower SMCs when it charges and higher SMCs when it discharges. Note that if the storage facility plays based on its marginal cost, the storage facility compared to a case in which there is no storage facility in the system, increases and decreases the market price in charging and discharging modes, respectively. The reason lies in supply and demand balance constraints. In an imperfect competition, as explained in Case 2, the facility through this strategic bidding avoids such impacts on market price. From this figure and also the results reflected in Table IV, the impact on prices in Case 2 benefits not only the storage facility, but also other generators. Overall, and among all the units, the peaking ones experience the highest increase in their profit as they only generate during the higher price hours.

\section{CONCLUSION}

This paper compares and studies the bidding strategy of a price-maker storage facility in both perfectly and imperfectly competitive markets. The storage operation in both market 


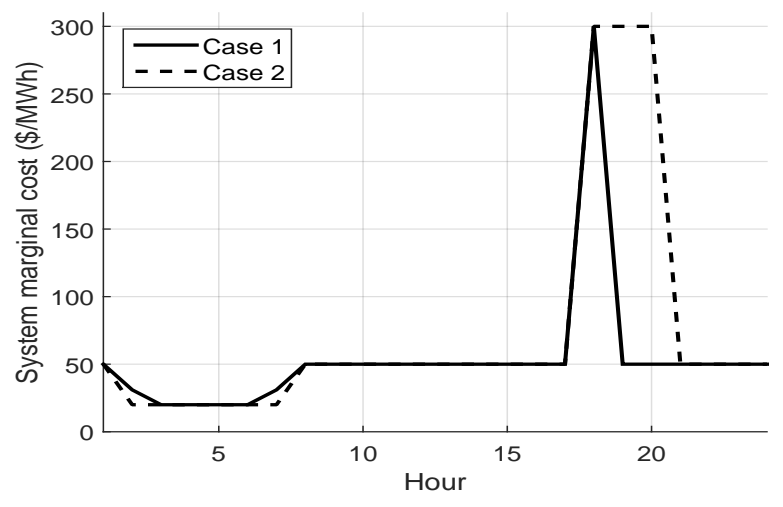

Figure 2. Comparing the hourly SMCs between Cases 1 and 2

structures is formulated. To model an imperfectly competition market, a bi-level model is implemented to present the interactions between the storage facility and the market operator. The primal-dual and KKT conditions are applied to transform the bi-level problem into an MPEC, that can be recast as a Mixed Integer Linear Programming (MILP). In both perfect and imperfect competitions, impacts of storage facility's operation decisions on hourly SMCs and generation schedule are presented and discussed. In an imperfect competition, the merchant storage facility was found to adjust its operation strategies to take advantage of existing circumstances in the market to increase its profit.

\section{APPENDIX}

The dual of the lower level problem is stated as follows:

$$
\begin{aligned}
& o_{s, t}^{d i s}-\lambda_{t}+\mu_{s, t}^{d i s, \max }-\mu_{s, t}^{d i s, \min }=0 \quad \forall s, \forall t \\
& -o_{s, t}^{c h}+\lambda_{t}+\mu_{s, t}^{c h, \max }-\mu_{s, t}^{c h, \min }=0 \quad \forall s, \forall t \\
& M C_{g}-\lambda_{t}+\mu_{g, t}^{\max }-\mu_{g, t}^{\min }=0 \quad \forall g, \forall t \\
& -U_{d, t}+\lambda_{t}+\mu_{d, t}^{\max }-\mu_{d, t}^{\min }=0 \quad \forall d, \forall t \\
& \mu_{g, t}^{\max }, \mu_{g, t}^{\min } \geq 0 \quad \forall g, \forall t \\
& \mu_{d, t}^{\max }, \mu_{d, t}^{\min } \geq 0 \quad \forall d, \forall t \\
& \mu_{s, t}^{d i s, \max }, \mu_{s, t}^{d i s, \min }, \mu_{s, t}^{c h, \max }, \mu_{s, t}^{c h, \min } \geq 0 \quad \forall s, \forall t \\
& \sum_{t=1}^{N_{t}}\left[\sum_{g=1}^{N_{g}} M C_{g} \cdot p_{g, t}+\sum_{s=1}^{N_{s}} o_{s, t}^{d i s} \cdot p_{s, t}^{d i s}\right. \\
& \left.-\sum_{s=1}^{N_{s}} o_{s, t}^{c h} \cdot p_{s, t}^{c h}-\sum_{d=1}^{N_{d}} U_{d, t} \cdot p_{d, t}\right]= \\
& -\sum_{t=1}^{N_{t}} \sum_{s=1}^{N_{s}}\left[\mu_{s, t}^{\text {dis, } \max } \cdot \bar{p}_{s, t}^{d i s}+\mu_{s, t}^{c h, \max } \cdot \bar{p}_{s, t}^{c h}\right] \\
& -\sum_{t=1}^{N_{t}} \sum_{g=1}^{N_{g}} \mu_{g, t}^{\max } \cdot P_{g}^{\max }-\sum_{t=1}^{N_{t}} \sum_{d=1}^{N_{d}}\left[\mu_{d, t}^{\max } \cdot P_{d, t}^{\max }\right]
\end{aligned}
$$

The KKT conditions of the lower level are stated as follows:

$$
\begin{aligned}
& 0 \leq p_{g, t} \perp \mu_{g, t}^{\text {min }} \geq 0 \quad \forall g, \forall t \\
& 0 \leq\left(P_{g}^{\text {max }}-p_{g, t}\right) \perp \mu_{g, t}^{\max } \geq 0 \quad \forall g, \forall t \\
& 0 \leq p_{d, t} \perp \mu_{d, t}^{\text {min }} \geq 0 \quad \forall d, \forall t \\
& 0 \leq\left(P_{d, t}^{\max }-p_{d, t}\right) \perp \mu_{d, t}^{\max } \geq 0 \quad \forall d, \forall t \\
& 0 \leq p_{s, t}^{\text {dis }} \perp \mu_{s, t}^{\text {dis,min }} \geq 0 \quad \forall s, \forall t \\
& 0 \leq\left(\bar{p}_{s, t}^{\text {dis }}-p_{s, t}^{\text {dis }}\right) \perp \mu_{s, t}^{\text {dis,max }} \geq 0 \quad \forall s, \forall t \\
& 0 \leq p_{s, t}^{c h} \perp \mu_{s, t}^{c h, \text { min }} \geq 0 \quad \forall s, \forall t \\
& 0 \leq\left(\bar{p}_{s, t}^{c h}-p_{s, t}^{c h}\right) \perp \mu_{s, t}^{c h, \max } \geq 0 \quad \forall s, \forall t
\end{aligned}
$$

The linearized objective function is stated as follows:

$$
\begin{aligned}
\text { Min. } & \sum_{t=1}^{N_{t}} \sum_{s=1}^{N_{s}}\left[M C_{s}^{d i s} \cdot p_{s, t}^{d i s}+M C_{s}^{c h} \cdot p_{s, t}^{c h}\right] \\
+ & \sum_{t=1}^{N_{t}} \sum_{g=1}^{N_{g}} M C_{g} \cdot p_{g, t}-\sum_{t=1}^{N_{t}} \sum_{d=1}^{N_{d}} U_{d, t} \cdot p_{d, t} \\
+ & \sum_{t=1}^{N_{t}} \sum_{g=1}^{N_{g}}\left[\mu_{g, t}^{\max } \cdot P_{g}^{\max }+\sum_{t=1}^{N_{t}} \sum_{d=1}^{N_{d}}\left[\mu_{d, t}^{\max } \cdot P_{d, t}^{\max }\right]\right.
\end{aligned}
$$

\section{REFERENCES}

[1] B. P. Roberts and C. Sandberg, "The role of energy storage in development of smart grids," Proceedings of the IEEE, vol. 99, no. 6, pp. 1139-1144, Jun. 2011.

[2] California Public Utilities Commission (CPUC), "Renewables portfolio standard program overview," Apr. 2011. [Online]. Available: http://www.cpuc.ca.gov/PUC/energy/Renewables/overview.htm

[3] California ISO (CAISO), "Final report for assessment of visibility and control options for distributed energy resources," Jun. 2012. [Online]. Available: http://www.caiso.com/Documents/FinalReport-AssessmentVisibility-ControlOptions-DistributedEnergyResources.pdf

[4] D. Hull, "California adopts first-in-nation energy storage plan," Oct. $2013 . \quad$ [Online]. Available: http://www.caiso.com/Documents/FinalReport-AssessmentVisibility-ControlOptions-DistributedEnergyResources.pdf

[5] S. Dahlke, "Grid-scale energy storage for integrating renewable energy: Updates on FERC order 755 and DOE-funded demonstration projects," 2012.

[6] H. Daneshi and A. K. Srivastava, "Security-constrained unit commitment with wind generation and compressed air energy storage," IET Generation, Transmission \& Distribution, vol. 6, no. 2, pp. 167-175, Feb. 2012.

[7] N. Li and K. Hedman, "Economic assessment of energy storage in systems with high levels of renewable resources," IEEE Transactions on Sustainable Energy, vol. 6, no. 3, pp. 1103-1111, Jun. 2015.

[8] P. Hu, R. Karki, and R. Billinton, "Reliability evaluation of generating systems containing wind power and energy storage," IET Generation, Transmission \& Distribution, vol. 3, no. 8, pp. 783-791, Aug. 2009.

[9] A. Y. Saber and G. K. Venayagamoorthy, "Plug-in vehicles and renewable energy sources for cost and emission reductions," IEEE Transactions on Industrial Electronics, vol. 58, no. 4, pp. 1229-1238, Apr. 2011.

[10] A. D. Lamont, "Assessing the economic value and optimal structure of large-scale electricity storage," IEEE Transactions on Power Systems, vol. 28, no. 2, pp. 911-921, May 2013.

[11] M. Dicorato, G. Forte, M. Pisani, and M. Trovato, "Planning and operating combined wind-storage system in electricity market," IEEE Transactions on Sustainable Energy, vol. 3, no. 2, pp. 209-217, Apr. 2012. 
[12] M. Parvania, M. Fotuhi-Firuzabad, and M. Shahidehpour, "Comparative hourly scheduling of centralized and distributed storage in day-ahead markets," IEEE Transactions on Sustainable Energy, vol. 5, no. 3, pp. 729-737, Jul. 2014.

[13] H. Akhavan-Hejazi and H. Mohsenian-Rad, "Optimal operation of independent storage systems in energy and reserve markets with high wind penetration," IEEE Transactions on Smart Grid, vol. 5, no. 2, pp. 1088-1097, Mar. 2014.

[14] H. Mohsenian-rad, "Coordinated price-maker operation of large energy storage units in nodal energy markets," IEEE Transactions on Power system, vol. 31, no. 1, pp. 786-797, Jan. 2016.

[15] B. F. Hobbs, C. B. Metzler, and J. S. Pang, "Strategic gaming analysis for electric power systems: An MPEC approach," IEEE Transactions on Power Systems, vol. 15, no. 2, pp. 638-645, May 2000.

[16] C. Ruiz and A. J. Conejo, "Pool strategy of a producer with endogenous formation of locational marginal prices," IEEE Transactions on Power Systems, vol. 24, no. 4, pp. 1855-1866, Nov. 2009.

[17] S. Wogrin, E. Centeno, and J. Barquin, "Generation capacity expansion in liberalized electricity markets: A stochastic MPEC approach," IEEE Transactions on Power Systems, vol. 26, no. 4, pp. 2526-2532, Nov. 2011.

[18] M. Zugno, J. M. Morales, P. Pinson, and H. Madsen, "Pool strategy of a price-maker wind power producer," IEEE Transactions on Power Systems, vol. 28, no. 3, pp. 3440-3450, Aug. 2013.

[19] S. J. Kazempour, A. J. Conejo, and C. Ruiz, "Strategic bidding for a large consumer," IEEE Transactions on Power Systems, vol. 30, no. 2, pp. 848-856, Mar. 2015.

[20] C. Sabu and M. R. Babu, "Nash equilibrium bidding strategies in a pool based electricity market," International Conference on Circuit, Power and Computing Technologies (ICCPCT), pp. 803-808, Mar. 2014.

[21] M. R. Hesamzadeh and M. Yazdani, "Transmission capacity expansion in imperfectly competitive power markets," IEEE Transactions on Power Systems, vol. 29, no. 1, pp. 62-71, Jan. 2014.

[22] S. A. Gabriel, A. J. Conejo, J. D. Fuller, B. F. Hobbs, and C. Ruiz, Complementarity modeling in energy markets. New York, USA, Springer, 2012.

[23] S. J. Kazempour, A. J. Conejo, and C. Ruiz, "Generation investment equilibria with strategic producers-part I: Formulation," IEEE Transactions on Power Systems, vol. 28, no. 3, pp. 2613-2622, Aug. 2013.

[24] J. Fortuny-Amat and B. McCarl, "A representation and economic interpretation of a two-level programming problem," The Journal of the Operational Research Society, vol. 32, no. 9, pp. 783-792, Sep. 1981.

[25] E. Nasrolahpour and H. Ghasemi, "A stochastic security constrained unit commitment model for reconfigurable networks with high wind power penetration," Electric Power Systems Research, vol. 121, pp. 341-350, Apr. 2015.

[26] S. Eckroad and I. Gyuk, "Handbook of energy storage for transmission or distribution applications," Technical Results, vol. 1007189, 2002.

[27] H. Safaei and D. W. Keith, "Compressed air energy storage with waste heat export: An Alberta case study," Energy Conversion and Management, vol. 78, pp. 114-124, Feb. 2014. 